\title{
Occupational exposure to solar ultraviolet $B$ radiation and risk of subtypes of breast cancer in Danish women
}

\author{
Julie Elbaek Pedersen (D) , Katrine Strandberg-Larsen, ${ }^{2}$ Michael Andersson, ${ }^{3}$ \\ Johnni Hansen ${ }^{1}$
}

- Additional material is published online only. To view please visit the journal online (http://dx.doi.org/10.1136 oemed-2020-107125).

Danish Cancer Society Research Center, Danish Cancer Society, Copenhagen, Denmark ${ }^{2}$ Department of Public Health, University of Copenhagen, Copenhagen, Denmark ${ }^{3}$ Department of Oncology, Rigshospitalet, Copenhagen, Denmark

\section{Correspondence to} Julie Elbaek Pedersen, Danish Cancer Society Research Center, Danish Cancer Society, Copenhagen 2100, Denmark; juliep@cancer.dk

Received 7 October 2020 Revised 30 November 2020 Accepted 7 December 2020 Published Online First 2 February 2021

\begin{abstract}
Objectives Previous epidemiological studies have indicated that solar ultraviolet B radiation (UVR) may have a protective effect on breast cancer. However, the evidence remains inconclusive. Despite the fact that outdoor work history may be considered a reliable measure of long-term UVR exposure, objective information on lifetime employment has not been included in previous investigations focusing on breast cancer. To address this issue, we explored the association between occupational UVR exposure and female breast cancer, including subtypes.
\end{abstract}

Methods A total of 38375 women under the age of 70 years were identified with primary breast cancer using the Danish Cancer Registry. Five female controls born on the same year, alive and free of breast cancer at the time of diagnosis of the index case, were randomly selected from the Danish Civil Registration System. The Danish Supplementary Pension Fund Register was used to retrieve full employment history, and a job exposure matrix was used to assess occupational UVR exposure. Conditional logistic regression with adjustment for important confounders was used to estimate the OR.

Results We observed no overall association between occupational UVR exposure and breast cancer. After the age of 50 years, longer duration of UVR exposure ( $\geq 20$ years: $O R=0.83,95 \% \mathrm{Cl} 0.75$ to 0.92 ) and highest cumulative exposure $(\mathrm{OR}=0.89,95 \% \mathrm{Cl} 0.83$ to 0.95$)$ were inversely associated with risk. Our results did not reflect any notable risk difference by oestrogen receptor status.

Conclusions This study indicates an inverse association between long-term occupational UVR exposure and lateonset breast cancer. This finding needs further attention in future occupational studies.

\section{INTRODUCTION}

Breast cancer is the most common cancer in women and the incidence has been rising over the last half of the 20th century. Acknowledged risk factors mainly include reproductive, lifestyle, medical and genetic factors, ${ }^{1}$ although these cannot explain all breast cancer cases or the increase in incidence rates. ${ }^{2}$

Vitamin D is essential for optimal health ${ }^{3}$ and it may have anticarcinogenic properties. These are likely mediated by the vitamin $\mathrm{D}$ receptor that controls the transcription of genes involved in cell proliferation, angiogenesis, cell differentiation and apoptosis, which are important biological processes

\section{Key messages}

What is already known about this subject?

- Solar ultraviolet B radiation (UVR) may have a protective effect on breast cancer; however, the evidence remains inconclusive due to methodological limitations in previous studies.

What are the new findings?

- This is the first study exploring the association between occupational UVR exposure and breast cancer using objective lifetime employment history.

- The findings indicate that long-term UVR may decrease the risk of late-onset breast cancer.

How might this impact on policy or clinical practice in the foreseeable future?

- Advice about regularly spending a short period of time outside in the sun could be considered especially for female indoor workers.

that are changed during carcinogenesis. ${ }^{4}$ Vitamin D is produced endogenously when solar ultraviolet $\mathrm{B}$ radiation (UVR) interacts with 7 -dehydrocholesterol in the skin. Other sources include dietary intake and supplementation, although UVR accounts for the majority of total vitamin D in healthy individuals. ${ }^{3}$

Despite the fact that sunlight is important for maintaining adequate vitamin D levels, there has been progress in the promotion of sun avoidance, which is mainly due to greater public awareness of UVR's harmful effects, for example, skin cancer, in more recent decades. ${ }^{5}$ In addition, the increase in the use of computers for both work and leisure time activities has resulted in people spending a higher proportion of their time in indoor rather than outdoor settings. ${ }^{6}$ Hence, it has been hypothesised that relatively recent modern behavioural patterns of sun avoidance, contributing to vitamin D deficiency worldwide, ${ }^{3}$ may be associated with the increase in breast cancer incidence rates.

A substantial body of literature has explored the association between circulating levels of vitamin D and breast cancer, and a recent meta-analysis ${ }^{7}$ has reported an inverse association with increasing levels. However, most of these studies are generally limited by postdiagnostic and few measurements of vitamin $\mathrm{D}$, which may not reflect usual long-term 
levels. In other explorations, different measures of UVR exposure have been used as surrogates for long-term vitamin $\mathrm{D},{ }^{8-21}$ and a recent meta-analysis of these epidemiological studies reported that ambient UVR, primarily based on residential latitude, was not associated with the risk of breast cancer, whereas self-reported time outdoors was inversely associated with risk. ${ }^{22}$ However, ambient measures may not reflect actual individuallevel UVR exposure, while self-reported measures may be susceptible to recall bias, which altogether limits the evidence.

A limited number of studies have included information on occupational UVR exposure, ${ }^{11} 141521$ which may be considered critical as employment history may be especially useful in ranking individuals according to lifetime UVR exposure. ${ }^{23}$ Workers in outdoor settings are exposed to considerably higher levels of UVR exposure compared with indoor workers, especially during the summer, as vitamin D synthesis mainly occurs between 10:00 and 15:00, that is, during normal working hours, in northern and southern latitudes. ${ }^{24} \mathrm{~A}$ recent systematic review supports this, as indoor workers were shown to have significantly lower levels of serum vitamin D compared with their outdoor counterparts, and this was attributed to less exposure to UVR. ${ }^{25}$ Hence, objective work history data reflecting outdoor activities may be a more reliable measure of long-term UVR exposure than ambient and self-reported measures.

To add to the sparse epidemiological evidence in this overall research area, we obtained large-scale, registry-based data on lifetime employment history to investigate the association between occupational UVR exposure and breast cancer, including subtypes, in a case-control study using a Danish job exposure matrix.

\section{METHODS}

All residents in Denmark are given a 10-digit personal identification number (PIN) from the Danish Civil Registration System (DCRS), which has systematically attained demographic information on all residents of Denmark since $1968 .^{26}$ The PIN is used as a unique key to all public administration, including individual-level register-based data on health and demography, and in the present study it was used to link information from relevant registries.

\section{Case and control selection}

Since 1943 all cancers diagnosed in Denmark have systematically been registered in the national Danish Cancer Registry ${ }^{27}$ according to various classifications: before 1978, an extended Danish version of the International Classification of Diseases Revision 7 (ICD-7) was used; between 1978 and 2003 ICD-O was used; and afterwards Revision 10 (ICD-10) was used. Primary breast cancer cases were identified in the study period ending in 2016 using converted codes according to ICD-10 (C50).

Work history was available from 1964 (see next section), and in order to ensure complete information on this from the age of 18, enabling an assessment of lifetime occupational UVR exposure, we restricted cases to women born in Denmark >1946. Consequently, the age at diagnosis for included cases was $\leq 70$ years. A total of 45787 cases who were born $\geq 1946$ were identified; however, we excluded 4065 cases as they were not born in Denmark and 3347 cases since registration on employment during the study period was lacking. After this process, a total of 38375 confirmed cases were included in the study. In addition, the clinical Danish Breast Cancer Cooperative
Group database ${ }^{28}$ was used to retrieve additional information on oestrogen receptor (ER) status during the period 1978-2015.

For each case, we used the incidence density sampling procedure to randomly select five female controls from the DCRS matched on the year of birth. They were also required to be born in Denmark and have employment history, and further to be alive and free of breast cancer at the time of diagnosis of the index case. After this process, a total of 191875 controls were included for analyses.

\section{Exposure assessment}

We retrieved full employment history from the Danish Supplementary Pension Fund Register (ATP), and registration in this registry was a prerequisite for eligibility in the study. ATP holds employment history on a company level, including information on start and end of each employment lasting at least 9 hours/ week, company name and a unique eight-digit company number for tax purposes backdating to 1964 for all wage earners in Denmark. All information is kept even if a company closes, or employees emigrate or die. ${ }^{29}$ Statistics Denmark has classified companies into a five-digit branch/industry code (in Danish: 'Danmarks Statistiks Erhvervsgrupperingskode, DSE') ${ }^{30}$ corresponding to an extended version of the four-digit International Standard Industrial Classification of all Economic Activities. ${ }^{29} 31$

The Nordic Occupational Cancer Study Job Exposure Matrix (NOCCA-JEM) ${ }^{32}$ entails converted UVR measurements reflecting exposure levels in Danish occupational settings, and this JEM was partly used to translate each employment held by the Danish women into occupational UVR exposure. However, as the original employment coding in the NOCCA-JEM is based on the Nordic Classification of Occupations (NYK), a Danish version of the JEM was constructed, and this was based on a crosswalk translating exposed NYK codes into Danish DSE codes. This translation was undertaken by a Danish occupational expert and coauthor of this article $(\mathrm{JH})$, and it also involved a further expert evaluation of each of the more detailed DSE codes. Thus, each industry representing various jobs was categorised according to presumed average occupational UVR exposure level (none, low, medium, high). To improve specificity, women with minimal occupational UVR exposure, that is, $<1$ year, were categorised as unexposed (see online supplemental table 1 for an overview of exposed industries).

\section{Covariates}

The presumed causal interplay of known or suspected risk factors for breast cancer is visualised in a directed acyclic graph (DAG) (online supplemental figure 1). Partly based on this DAG and availability of information, socioeconomic status (SES) and reproductive factors, that is, parity and age at first live birth, were included from the DCRS, which updates the demographic information of all residents on a daily basis. SES was based on self-reported information on job title, which initially originated from annual tax returns or official change of address forms. This information was categorised according to SES using the Danish Institute of Social Sciences' definition: academics ( $\geq 5$ years), middle education (3-4.5 years), shorter education ( $2-3$ years) following high school, skilled workers and unskilled workers. ${ }^{33}$ Further, an additional group consisted of women with missing information on job title, which included approximately $22 \%$ of our study population. Full information on reproductive factors relating to childbirth was available, including parity $(0,1-2$, $\geq 3)$ and the exact age at first live birth $(<25,25-29,30-34$ and $\geq 35$ ). In addition, possible confounding by work-related 
physical activity was assessed by also using a Danish version of the NOCCA-JEM, and this information was categorised according to ever versus never working in a job with 'heavy or rather heavy physical activity'.

\section{Statistical analysis}

To evaluate the association between occupational UVR exposure and breast cancer, including subtypes by ER status, conditional logistic regression for matched data sets was used to calculate the OR with corresponding 95\% CI. In the fully adjusted models, age at first live birth, parity and work-related physical activity were included, and succeeding multivariable analyses restricted to women with no missing information on SES were conducted as well, which virtually yielded similar results (data not shown). Further analyses were undertaken stratifying according to women's age at the index date $(<50, \geq 50$ years old), which was used as a proxy for menopausal status.

In the overall analyses, we explored ever versus never being exposed to UVR in an occupational setting as well as the duration of exposure and cumulative exposure. We calculated duration of exposure by summing the years of employment in all exposed jobs (1-9years, 10-20years, >20years). Further, cumulative exposure was defined as the product of duration and level of exposure in each exposed job, which was summed over the woman's employment history, and the categorisation was based on the percentiles among the exposed controls $(>0-25$, $>25-50,>50-75,>75)$. To explore potential duration and dose-response relationships, we conducted trend tests using ordinal scores.

As the time before first pregnancy is considered a window of susceptibility for breast cancer ${ }^{34}$ and self-reported UVR exposure in younger ages has been indicated to have a protective effect on breast cancer, ${ }^{22}$ it was hypothesised a priori that UVR exposure in this period could particularly have a beneficial effect on the risk. Moreover, vitamin D status near the time of diagnosis has been inversely associated with risk of breast cancer, indicating that vitamin D may also affect late stages of tumour development. ${ }^{35}$ Thus, analyses exploring the impact of UVR exposure according to first live birth (before vs after) and in the last held job before index date (yes vs no) were conducted as well.

All analyses were performed with Stata V.14.2 statistical software.

\section{RESULTS}

The distribution of acknowledged risk factors was largely consistent with current knowledge, that is, cases generally had higher SES, lower parity and older age at first liveborn child, although they were marginally more likely to have been employed in work with physical activity. The distribution of hormonal cancer subtypes also followed an expected pattern as a relatively larger proportion of cases were diagnosed with ER+ tumours (table 1).

The adjusted results showed no notable effect of occupational UVR exposure on the overall risk of breast cancer, although the risk tended to decrease with longer duration of exposure ( $\geq 20$ years: $\mathrm{OR}=0.85,95 \%$ CI 0.78 to 0.93 ) (table 2 ).

Results for early-onset breast cancer (before age 50 years) did not indicate any important duration and dose-response relationships for UVR exposure and risk of breast cancer. For lateonset cancer (after age 50 years), the risk slightly decreased with longer duration of exposure ( $\geq 20$ years: $\mathrm{OR}=0.83,95 \% \mathrm{CI} 0.75$ to 0.92$)$ and higher cumulative exposure $(>75 \%$ : $\mathrm{OR}=0.89$, $95 \%$ CI 0.83 to 0.95 ) (table 3 ).
Table 1 Characteristics of breast cancer cases and their matched controls in the study population of Danish women

\begin{tabular}{|c|c|c|}
\hline & Cases $(n=38375)(\%)$ & $\begin{array}{l}\text { Controls } \\
(n=191875)(\%)\end{array}$ \\
\hline \multicolumn{3}{|l|}{ Socioeconomic status } \\
\hline Academics & $1870(4.9)$ & $9142(4.8)$ \\
\hline Middle education & $4141(10.8)$ & $18244(9.5)$ \\
\hline Shorter education & 6709 (17.5) & $32651(17.1)$ \\
\hline Skilled & $9165(23.9)$ & $46539(24.2)$ \\
\hline Unskilled & 7977 (20.8) & $42324(22.1)$ \\
\hline Unknown & $8513(22.1)$ & $42875(22.3)$ \\
\hline \multicolumn{3}{|l|}{ Reproductive factors } \\
\hline \multicolumn{3}{|l|}{ Number of children } \\
\hline 0 & $4572(11.9)$ & $20865(10.9)$ \\
\hline $1-2$ & $32136(83.8)$ & $160509(83.7)$ \\
\hline$\geq 3$ & $1667(4.3)$ & $10501(5.4)$ \\
\hline Mean number $( \pm S D)$ & $1.8(1.0)$ & $1.9(1.0)$ \\
\hline \multicolumn{3}{|l|}{ Age at first live birth* } \\
\hline$<25$ & $17441(51.6)$ & $93141(54.4)$ \\
\hline $25-29$ & $10549(31.2)$ & $52367(30.6)$ \\
\hline $30-34$ & $4368(12.9)$ & $18913(11.1)$ \\
\hline$\geq 35$ & $1445(4.3)$ & $6589(3.9)$ \\
\hline Mean age $( \pm S D)$ & $27.2(5.7)$ & $26.9(5.7)$ \\
\hline \multicolumn{3}{|c|}{ Work-related physical activity } \\
\hline Ever & $19483(50.7)$ & $96184(50.1)$ \\
\hline Never & $18892(49.3)$ & $95691(49.9)$ \\
\hline \multicolumn{3}{|c|}{ Subtypes of breast cancer } \\
\hline \multicolumn{3}{|l|}{ ER status } \\
\hline Negative & $7063(18.5)$ & \\
\hline Positive & $26085(67.9)$ & \\
\hline Missing & 5227 (13.6) & \\
\hline
\end{tabular}

The results did not reflect a noteworthy risk difference by ER status as both subtypes tended to decrease with longer duration of exposure (table 4).

However, more convincing inverse risk patterns were indicated for late onset of both hormonal subtypes (table 5).

When examining the risk by timing of exposure according to first live birth and last held job, no striking risk differences were generally observed (tables 2-4). Adjustment for the selected potential confounders generally did not impact risk estimates in any analysis (data with unadjusted results not shown).

\section{DISCUSSION}

The present study indicates that long-term occupational UVR exposure is associated with a modestly reduced risk of breast cancer, and our further analyses indicated duration and doseresponse relationships for UVR exposure and risk of late-onset breast cancer. No notable difference in risk of breast cancer was observed by ER status.

Incidence studies on UVR exposure and risk of breast cancer overall demonstrate inconsistent findings, supporting either an inverse association ${ }^{8-15} 21$ or no association. ${ }^{16-20}$ The inconsistency in existing studies may partly be due to the use of different measures for UVR exposure, including ambient UVR, mostly based on latitude of residence, as well as self-reported time spent outdoors. Thus, a recent meta-analysis by Hiller $e t a l^{22}$ reported that ambient UVR was not associated with breast cancer, whereas women reporting spending $\geq 1$ hour per day outdoors during the summer months in adulthood had a decreased relative risk of 
Table 2 Observed number of exposed cases and controls and OR with $95 \% \mathrm{Cl}$ for breast cancer in Danish women by proxies for occupational UVR exposure

\begin{tabular}{|c|c|c|c|c|}
\hline & Cases & Controls & OR* & $95 \% \mathrm{Cl}$ \\
\hline Overall & 7825 & 38933 & 0.99 & 0.97 to 1.02 \\
\hline \multicolumn{5}{|c|}{ Duration of exposure (years) } \\
\hline $1-9$ & 6109 & 29860 & 1.01 & 0.98 to 1.04 \\
\hline $10-20$ & 1113 & 5603 & 0.98 & 0.92 to 1.05 \\
\hline$>20$ & 603 & 3470 & 0.85 & 0.78 to 0.93 \\
\hline Trend test ( $p$ value) & & 0.10 & & \\
\hline \multicolumn{5}{|l|}{ Cumulative exposuret } \\
\hline$>0 \%-25 \%$ & 1956 & 9712 & 0.99 & 0.95 to 1.05 \\
\hline$>25 \%-50 \%$ & 2040 & 9720 & 1.04 & 0.99 to 1.09 \\
\hline$>50 \%-75 \%$ & 1975 & 9766 & 1.00 & 0.95 to 1.05 \\
\hline$>75 \%$ & 1854 & 9735 & 0.94 & (0.89 to 1.00$)$ \\
\hline Trend test ( $p$ value) & & & 0.40 & \\
\hline \multicolumn{5}{|l|}{ Timing of first exposureł } \\
\hline Prior to first live birth & 4299 & 20872 & 1.02 & 0.98 to 1.05 \\
\hline After first live birth & 2627 & 13783 & 0.98 & 0.93 to 1.02 \\
\hline \multicolumn{5}{|l|}{ Exposure in last held job§ } \\
\hline No & 5971 & 29820 & 0.99 & 0.96 to 1.02 \\
\hline Yes & 1854 & 9113 & 1.01 & 0.96 to 1.06 \\
\hline
\end{tabular}

${ }^{*}$ Adjusted for parity, age at first live birth and work-related physical activity.

†Exposure level ${ }^{*}$ years summed over employment history and categorised according to percentiles among the controls.

$\ddagger$ Among parous women.

$\S$ Among women with lifetime occupational UVR exposure.

UVR, ultraviolet $B$ radiation.

breast cancer compared with those spending less time, that is, $<1$ hour per day ( $R R=0.84,95 \%$ CI 0.77 to 0.91$)$. Our results are thereby supported by studies mostly using self-reported time spent outdoors as proxy for UVR exposure, which may be considered a more reliable measure of true UVR exposure than ambient measures.

Only a few of these epidemiological studies have incorporated occupation as a source of UVR exposure, including the prospective cohort study among 5009 women by John et al, ${ }^{11}$ reporting that self-reported frequent occupational sun exposure reduced the overall risk of breast cancer $(\mathrm{RR}=0.64,95 \% \mathrm{CI} 0.41$ to 0.98$)$. In an agricultural health study by Engel et $a l^{14}$ including 293 cases and 586 controls, wives of farmers reporting usual sun exposure of $\geq 1$ hour per day 10 years prior to follow-up were also observed to have a reduced overall risk of breast cancer $(\mathrm{HR}=0.8,95 \% \mathrm{CI} 0.6$ to 1.0$)$. Knight et $a l^{15}$ including 972 cases and 1135 controls observed an inverse association between self-reported number of years of working outdoors and breast cancer, but only at ages 10-19 ( $\geq 1$ year of employment: $\mathrm{OR}=0.61,95 \% \mathrm{CI} 0.46$ to 0.80 ). In a subsequent study based on the same study population including 759 cases and 1135 controls, Blackmore et $a l^{21}$ examined the risk of hormonal subtypes of breast cancer and detected an increased risk of all subtypes among women with occupational UVR exposure.

Although Hiller $e t \mathrm{al}^{22}$ reported that only self-reported exposure in younger ages, that is, $<40$ years of age, was indicated to have a protective effect, our results indicated no reduced risk with exposure before first live birth. Previous studies based on both ambient and self-reported measures examining timing of UVR exposure and breast cancer are few and generally show inconsistent results, ${ }^{8} 1215161920$ and exposure time windows therefore need to be studied further. In addition, we did not detect a reduced risk in women with UVR exposure in their last held job, and our results are therefore conflicting with a recent review supporting an inverse association between serum vitamin D status close to index date and risk of breast cancer. ${ }^{35}$ However, important limitations exist in some studies detecting this association, including postdiagnostic measurements.

Table 3 Observed number of exposed cases and controls and OR with $95 \% \mathrm{Cl}$ for breast cancer before and after the age of 50 years in Danish women by proxies for occupational UVR exposure

\begin{tabular}{|c|c|c|c|c|c|c|c|c|}
\hline & \multicolumn{4}{|c|}{$<50$ years } & \multicolumn{4}{|c|}{$\geq 50$ years } \\
\hline & Cases & Controls & $\mathrm{OR}^{*}$ & $95 \% \mathrm{Cl}$ & Cases & Controls & $O R^{*}$ & $95 \% \mathrm{Cl}$ \\
\hline Overall & 3319 & 16125 & 1.02 & 0.98 to 1.07 & 4506 & 22808 & 0.97 & 0.94 to 1.01 \\
\hline \multicolumn{9}{|c|}{ Duration of exposure (years) } \\
\hline $1-9$ & 2674 & 13071 & 1.02 & 0.97 to 1.07 & 3435 & 16789 & 1.01 & 0.97 to 1.05 \\
\hline $10-20$ & 484 & 2218 & 1.08 & 0.97 to 1.19 & 629 & 3385 & 0.92 & 0.84 to 1.00 \\
\hline$>20$ & 161 & 836 & 0.94 & 0.80 to 1.12 & 442 & 2634 & 0.83 & 0.75 to 0.92 \\
\hline Trend test ( $p$ value) & & & 0.25 & & & & 0.00 & \\
\hline \multicolumn{9}{|l|}{ Cumulative exposuret } \\
\hline$>0 \%-25 \%$ & 780 & 4016 & 0.96 & 0.89 to 1.04 & 1169 & 5674 & 1.01 & 0.95 to 1.08 \\
\hline$>25 \%-50 \%$ & 848 & 4046 & 1.05 & 0.97 to 1.13 & 1178 & 5722 & 1.01 & 0.95 to 1.08 \\
\hline$>50 \%-75 \%$ & 842 & 4031 & 1.04 & 0.96 to 1.12 & 1129 & 5707 & 0.97 & 0.91 to 1.04 \\
\hline$>75 \%$ & 849 & 4032 & 1.04 & 0.97 to 1.13 & 1030 & 5705 & 0.89 & 0.83 to 0.95 \\
\hline Trend test ( $p$ value) & & & 0.08 & & & & 0.01 & \\
\hline \multicolumn{9}{|c|}{ Timing of first exposure } \\
\hline Prior to first live birth & 2042 & 9748 & 1.05 & 1.00 to 1.11 & 2257 & 11124 & 0.99 & 0.94 to 1.04 \\
\hline After first live birth & 847 & 4456 & 1.01 & 0.94 to 1.10 & 1780 & 9327 & 0.96 & 0.91 to 1.01 \\
\hline \multicolumn{9}{|c|}{ Exposure in last held job§ } \\
\hline No & 2440 & 11922 & 1.01 & 0.97 to 1.06 & 3531 & 17898 & 0.97 & 0.93 to 1.01 \\
\hline Yes & 879 & 4203 & 1.04 & 0.97 to 1.13 & 975 & 4910 & 0.98 & 0.91 to 1.05 \\
\hline
\end{tabular}

${ }^{*}$ Adjusted for parity, age at first live birth and work-related physical activity.

tExposure level ${ }^{*}$ years summed over employment history and categorised according to percentiles among the controls.

$\ddagger$ Among parous women.

$\S$ Among women with lifetime occupational UVR exposure.

UVR, ultraviolet $B$ radiation. 
Table 4 Observed number of exposed cases and controls and OR with $95 \% \mathrm{Cl}$ for subtypes of breast cancer, that is, by ER status, by proxies for occupational UVR exposure

\begin{tabular}{|c|c|c|c|c|c|c|c|c|}
\hline & \multicolumn{4}{|l|}{ ER- } & \multicolumn{4}{|l|}{ ER+ } \\
\hline & Cases & Controls & $\mathrm{OR}^{*}$ & $95 \% \mathrm{Cl}$ & Cases & Controls & $\mathrm{OR}^{*}$ & $95 \% \mathrm{Cl}$ \\
\hline Ever & 1387 & 6935 & 1.00 & 0.93 to 1.06 & 5462 & 26858 & 1.01 & 0.97 to 104 \\
\hline \multicolumn{9}{|c|}{ Duration of exposure (years) } \\
\hline $1-9$ & 1090 & 5437 & 1.00 & 0.93 to 1.07 & 4231 & 20384 & 1.03 & 0.99 to 1.07 \\
\hline $10-20$ & 201 & 939 & 1.06 & 0.91 to 1.24 & 783 & 3954 & 0.98 & 0.91 to 1.06 \\
\hline$>20$ & 96 & 559 & 0.85 & 0.68 to 1.06 & 448 & 2520 & 0.88 & 0.79 to 0.97 \\
\hline Trend test ( $p$ value) & & 0.75 & & & & & 0.46 & \\
\hline \multicolumn{9}{|l|}{ Cumulative exposure $†$} \\
\hline$>0 \%-25 \%$ & 325 & 1726 & 0.94 & 0.83 to 1.06 & 1380 & 6701 & 1.02 & 0.96 to 1.08 \\
\hline$>25 \%-50 \%$ & 358 & 1735 & 1.03 & 0.91 to 1.16 & 1421 & 6720 & 1.05 & 0.99 to 1.11 \\
\hline$>50 \%-75 \%$ & 357 & 1740 & 1.02 & 0.91 to 1.15 & 1383 & 6720 & 1.02 & 0.96 to 1.08 \\
\hline$>75 \%$ & 347 & 1734 & 0.99 & 0.88 to 1.12 & 1278 & 6717 & 0.94 & 0.89 to 1.00 \\
\hline Trend test ( $p$ value) & & & 0.73 & & & & 0.84 & \\
\hline \multicolumn{9}{|c|}{ Timing of first exposureł } \\
\hline Prior to first live birth & 758 & 3797 & 1.01 & 0.93 to 1.10 & 3006 & 14220 & 1.04 & 1.00 to 1.09 \\
\hline After first live birth & 457 & 2357 & 0.97 & 0.88 to 1.01 & 1860 & 9694 & 0.99 & 0.94 to 1.04 \\
\hline \multicolumn{9}{|c|}{ Exposure in last held job§ } \\
\hline No & 1035 & 5251 & 0.98 & 0.91 to 1.06 & 4208 & 20661 & 1.01 & 0.97 to 1.05 \\
\hline Yes & 352 & 1684 & 1.04 & 0.93 to 1.17 & 1254 & 6197 & 1.01 & 0.95 to 1.07 \\
\hline
\end{tabular}

${ }^{*}$ Adjusted for parity, age at first live birth and work-related physical activity.

tExposure level *years summed over employment history and categorised according to percentiles among the controls.

$\ddagger$ Among parous women.

$\S$ Among women with lifetime occupational UVR exposure.

$E R$, oestrogen receptor; UVR, ultraviolet $B$ radiation.

Skin adaptation from regular exposure to solar UVR at work may also explain why women in their last held job were not observed to have a reduced breast cancer risk. In particular, thickening of the stratum corneum part of the skin, induced by regular exposure to solar UVR, may lead to increased protection against UVR by a factor of five or even higher and may thereby also lead to a reduced production of vitamin D.

We only observed a reduced risk of breast tumours after the age of 50 years, approximating postmenopausal status, following long-term UVR exposure. Relatively few studies in this research area have explored the risk by menopausal status, ${ }^{8} 91415$ and no evidence of difference in associations has generally been reported, although one study observed a more pronounced reduced risk of postmenopausal breast cancer in women living in regions with higher UVR exposure, ${ }^{9}$ which in part confirms our observation.

No noteworthy difference in the reduction of risk of hormonal cancers after the age of 50 years was indicated by our results. A limited number of epidemiological studies have examined the risk by ER status as well and the evidence is inconsistent. ${ }^{13142021}$ Therefore, subtypes of breast cancer should be addressed further in future studies as well.

Our results showing an inverse association between long-term occupational UVR exposure level and late-onset breast cancer

Table 5 Observed number of exposed cases (obs) and OR with $95 \% \mathrm{Cl}$ for subtypes of breast cancer, that is, by ER status, before and after the age of 50 years in Danish women by proxies for occupational UVR exposure

\begin{tabular}{|c|c|c|c|c|c|c|c|c|c|c|c|c|}
\hline & \multicolumn{6}{|c|}{$<50$ years } & \multicolumn{6}{|c|}{$\geq 50$ years } \\
\hline & \multicolumn{3}{|l|}{ ER- } & \multicolumn{3}{|l|}{ ER+ } & \multicolumn{3}{|l|}{ ER- } & \multicolumn{3}{|l|}{ ER+ } \\
\hline & Obs & $\mathrm{OR}^{*}$ & $95 \% \mathrm{Cl}$ & Obs & $\mathrm{OR}^{*}$ & $95 \% \mathrm{Cl}$ & Obs & $O R^{*}$ & $95 \% \mathrm{Cl}$ & Obs & $\mathrm{OR}^{*}$ & $95 \% \mathrm{Cl}$ \\
\hline Ever & 746 & 1.02 & 0.93 to 1.11 & 2112 & 1.06 & 0.99 to 1.11 & 641 & 0.97 & 0.88 to 1.06 & 3350 & 0.98 & 0.94 to 1.02 \\
\hline \multicolumn{13}{|c|}{ Duration of exposure (years) } \\
\hline $1-9$ & 596 & 1.00 & 0.90 to 1.10 & 1688 & 1.05 & 0.99 to 1.11 & 494 & 1.00 & 0.90 to 1.11 & 2543 & 1.01 & 0.97 to 1.06 \\
\hline $10-20$ & 114 & 1.14 & 0.93 to 1.41 & 311 & 1.11 & 0.98 to 1.26 & 87 & 0.97 & 0.77 to 1.23 & 472 & 0.91 & 0.82 to 1.00 \\
\hline$>20$ & 36 & 1.11 & 0.77 to 1.60 & 113 & 0.99 & 0.80 to 1.21 & 60 & 0.75 & 0.57 to 0.98 & 335 & 0.85 & 0.75 to 0.95 \\
\hline Trend test ( $p$ value) & 0.31 & & & 0.04 & & & 0.17 & & & 0.02 & & \\
\hline \multicolumn{13}{|c|}{ Cumulative exposuret } \\
\hline$>0 \%-25 \%$ & 159 & 0.87 & 0.73 to 1.04 & 502 & 1.00 & 0.90 to 1.10 & 166 & 1.00 & 0.83 to 1.17 & 872 & 1.02 & 0.94 to 1.10 \\
\hline$>25 \%-50 \%$ & 187 & 1.03 & 0.87 to 1.21 & 531 & 1.08 & 0.98 to 1.19 & 178 & 1.07 & 0.88 to 1.24 & 879 & 1.03 & 0.95 to 1.11 \\
\hline$>50 \%-75 \%$ & 200 & 1.10 & 0.93 to 1.28 & 544 & 1.08 & 0.98 to 1.19 & 154 & 0.92 & 0.74 to 1.07 & 841 & 0.98 & 0.91 to 1.06 \\
\hline$>75 \%$ & 200 & 1.09 & 0.93 to 1.28 & 535 & 1.07 & 0.97 to 1.18 & 143 & 0.86 & 0.69 to 1.00 & 758 & 0.89 & 0.82 to 0.96 \\
\hline Trend test ( $p$ value) & 0.17 & & & 0.01 & & & 0.24 & & & 0.05 & & \\
\hline
\end{tabular}

${ }^{*}$ Adjusted for parity, age at first live birth and work-related physical activity.

†Exposure level ${ }^{*}$ years summed over employment history and categorised according to percentiles among the controls.

$E R$, oestrogen receptor; UVR, ultraviolet $B$ radiation. 
are believed to be largely mediated by contentious sufficient vitamin D levels. Vitamin D has been shown to have anticarcinogenic properties by affecting important biological processes, including cell proliferation, angiogenesis, cell differentiation and apoptosis. ${ }^{4}$ Some alternative mechanisms have also been suggested, including the effect of sunlight on circadian rhythm. Sun exposure during the day can increase melatonin peak levels at night, which may have anti-cell proliferative effects. ${ }^{36}$ Nevertheless, the present study cannot confirm any of these hypotheses. However, the potential pathway involving vitamin D is supported by evidence from a recent meta-analysis ${ }^{7}$ suggesting an inverse association between circulating levels of vitamin D and breast cancer, although several of the included studies may have been limited by few as well as postdiagnostic measurements, which do not reflect usual long-term vitamin D levels.

Despite the fact that solar UVR in countries at higher latitudes, including Denmark, is only intense enough during the summer months to have a significant effect on skin synthesis of vitamin $\mathrm{D}$, vitamin $\mathrm{D}$ can be stored in adipose tissue for release during periods of vitamin D deficiency. ${ }^{37}$ This mechanism may in part explain the results from a recent study among UK population groups showing that regular UVR exposure during the summer prevented vitamin D deficiency through the winter. ${ }^{38}$ Thus, occupational UVR exposure during the summer in Danish women may secure sufficient vitamin D levels in the winter as well.

There are some limitations to our study that need to be addressed. Despite the fact that sun exposure is considered the most important source of vitamin D for most people, dietary intake and supplementation are also sources of vitamin $\mathrm{D},{ }^{3}$ which may be especially important among groups with low exposure to sunlight. However, lack of information on other sources of vitamin D may not have been critical in our study when ranking women according to long-term vitamin D levels using occupational UVR exposure as proxy, since indoor workers have been shown to have significantly lower levels of serum vitamin D compared with their outdoor counterparts, which was attributed to less exposure to UVR. ${ }^{25}$

There are some restrictions to the use of employment data from the ATP registry, which include that information on periods with self-employment is not available, for example, self-employed farmers, who earlier constituted relatively large groups. ${ }^{29}$ Hence, UVR exposure in women self-employed in this profession may have been underestimated in our study. Moreover, each woman working in the same industry was assigned the same exposure, although there may be exposure variance due to different factors, including different held jobs and work tasks. Hence, we lacked information on several work characteristics and environmental factors (eg, job title, work tasks, hours of daily work and sun protection behaviours), which all influence individual-level UVR exposure. Therefore, our exposure assessment was relatively crude and may have involved unavoidable non-differential misclassification.

On the other hand, Hiller et $a l^{22}$ observed that $\geq 2$ hours per day in the sun did not afford any additional benefit regarding risk of breast cancer compared with 1-2 hours per day. Moreover, no pattern of association with risk of breast cancer has generally been reported in studies accounting for factors potentially modifying individual-level vitamin D production, for example, use of sunscreen ${ }^{81420}$ as well as sun-sensitive factors (eg, hair/eye colour and skin pigmentation/ethnicity). ${ }^{8-10} 12-15171920$ These observations may be partly explained by the fact that relatively short time in the sun, that is, less than half an hour per day, is enough to secure maximal levels of vitamin $\mathrm{D}$, and that additional time may not increase the levels further. ${ }^{39}$ Consequently, an exact estimation of cumulative UVR exposure may not be imperative when exploring the association with breast cancer, but rather an evaluation of the likelihood of regular UVR exposure on a longterm basis. Thus, our somewhat crude UVR exposure assessment based on objective employment history may still be considered useful.

We did not have information on other sources of UVR exposure, that is, leisure time spent outdoors and sunbathing vacations. UVR exposure levels at leisure and after working hours have not been reported to differ between indoor and outdoor workers ${ }^{24}$; thus, occupational UVR may conceivably explain the lower serum vitamin D levels observed in indoor workers compared with outdoor workers. ${ }^{25}$ Moreover, previous studies have not detected any association between breast cancer and lifetime sunbathing vacations ${ }^{1720}$ as well as sunburns, ${ }^{10} 1215171920$ indicating that more intermittent sun exposure may have limited effect on risk of breast cancer. Hence, employment history may be more important in predicting high versus low long-term UVR exposure and contentious vitamin D status than leisure time spent outdoors and sunbathing vacations, and lack of information on these other sources of UVR exposure may therefore not have been a key restriction in our study.

Information on lifestyle factors, including use of oral contraceptives, hormone replacement therapy, obesity, alcohol consumption and physical inactivity, was not available and may thus have confounded our results. However, previous studies adjusting for leisure time physical activity ${ }^{814} 15$ and other lifestyle variables ${ }^{8911} 13151718$ have reported no or minimal alteration in risk estimates, and lack of this information in our study is therefore not presumed to have been critical as well. Our inverse associations may also be due to chance as we did not account for multiple comparisons. Instead we focused on discussing our findings according to biological plausibility and existing evidence, which, it has been argued, will lead to fewer errors of interpretation. ${ }^{40}$

To the authors' knowledge, this is the first study exploring the association between occupational UVR exposure and breast cancer using objective lifetime employment history, which is likely a more accurate indicator of actual exposure than crosssectional ambient measures, and a more reliable measure of long-term exposure than self-reports. Moreover, we used a JEM particularly developed to assess occupational UVR exposure in Danish women, and we were able to explore duration and doseresponse relationships as well as time windows of exposure. A strength was also the large-scale, case-control design with a high number of incident breast cancer cases, including information on hormonal subtypes, which were retrieved from reliable nationwide cancer registries.

\section{CONCLUSION}

This large-scale, population-based, case-control study indicates that occupational UVR exposure may have a slightly protective effect on the risk of breast cancer after the age of 50, independent of hormonal receptor status. This association needs to be confirmed in future studies with more refined analyses including important confounders.

Acknowledgements We thank the Danish Breast Cancer Cooperative Group for providing clinical data on breast cancer for the study.

Contributors JEP contributed substantially to the conception of the study, performed the analyses, interpreted the results and wrote the manuscript. KS-L and MA contributed to the conception of the study, interpreted the results and revised the manuscript critically. JH was a key contributor in the design process of the study 
and the analyses that were undertaken, and revised the manuscript critically for important intellectual content. All authors have approved the final version to be published and are accountable for all aspects of the work.

Funding The authors have not declared a specific grant for this research from any funding agency in the public, commercial or not-for-profit sectors.

Competing interests None declared.

Patient consent for publication Not required.

Ethics approval The research has been notified to the Danish Data Protection Agency and it has been carried out in concordance with the requirements relating to the use of non-sensitive data about participants. As an ethical approval for undertaking purely register-based research is not needed in Denmark, this was not attained.

Provenance and peer review Not commissioned; externally peer reviewed.

Data availability statement No data are available.

Supplemental material This content has been supplied by the author(s). It has not been vetted by BMJ Publishing Group Limited (BMJ) and may not have been peer-reviewed. Any opinions or recommendations discussed are solely those of the author(s) and are not endorsed by BMJ. BMJ disclaims all liability and responsibility arising from any reliance placed on the content. Where the content includes any translated material, BMJ does not warrant the accuracy and reliability of the translations (including but not limited to local regulations, clinical guidelines, terminology, drug names and drug dosages), and is not responsible for any error and/or omissions arising from translation and adaptation or otherwise.

ORCID ID

Julie Elbaek Pedersen http://orcid.org/0000-0001-5158-696X

\section{REFERENCES}

1 Labrèche F, Goldberg MS, Weiderpass E. Breast Cancer. In: Anttila S, Boffetta P, eds. Occupational cancers. London: Springer London, 2014: 391-408.

2 Harris JR, Lippman ME, Veronesi U, et al. Breast cancer (1). N Engl J Med 1992;327:319-28.

3 Holick MF, Chen TC. Vitamin D deficiency: a worldwide problem with health consequences. Am J Clin Nutr 2008;87:1080S-6.

4 Narvaez CJ, Matthews D, LaPorta E, et al. The impact of vitamin D in breast cancer: genomics, pathways, metabolism. Front Physiol 2014;5:213.

5 IARC. IARC monographs on the evaluation of carcinogenic risks to humans. solar and ultraviolet radiation. IARC Monogr Eval Carcinog Risks Hum 1992;55:1-316.

6 van der Rhee HJ, de Vries E, Coebergh JW. Regular sun exposure benefits health. Med Hypotheses 2016:97:34-7.

7 Hossain S, Beydoun MA, Beydoun HA, et al. Vitamin D and breast cancer: a systematic review and meta-analysis of observational studies. Clin Nutr ESPEN 2019;30:170-84.

8 Anderson LN, Cotterchio M, Kirsh VA, et al. Ultraviolet sunlight exposure during adolescence and adulthood and breast cancer risk: a population-based case-control study among Ontario women. Am J Epidemio/ 2011;174:293-304.

9 Engel P, Fagherazzi G, Mesrine $S$, et al. Joint effects of dietary vitamin D and sun exposure on breast cancer risk: results from the French E3N cohort. Cancer Epidemiol Biomarkers Prev 2011;20:187-98.

10 John EM, Schwartz GG, Koo J, et al. Sun exposure, vitamin D receptor gene polymorphisms, and breast cancer risk in a multiethnic population. Am J Epidemiol 2007:166:1409-19.

11 John EM, Schwartz GG, Dreon DM, et al. Vitamin D and breast cancer risk: the NHANES I epidemiologic follow-up study, 1971-1975 to 1992. National health and nutrition examination survey. Cancer Epidemiol Biomarkers Prev 1999;8:399-406.

12 Yang L, Veierød MB, Löf $M$, et al. Prospective study of UV exposure and cancer incidence among Swedish women. Cancer Epidemiol Biomarkers Prev 2011;20:1358-67.

13 Millen AE, Pettinger M, Freudenheim JL, et al. Incident invasive breast cancer geographic location of residence, and reported average time spent outside. Cancer Epidemiol Biomarkers Prev 2009;18:495-507.
14 Engel LS, Satagopan J, Sima CS, et al. Sun exposure, vitamin D receptor genetic variants, and risk of breast cancer in the agricultural health study. Environ Health Perspect 2014;122:165-71.

15 Knight JA, Lesosky M, Barnett $H$, et al. Vitamin D and reduced risk of breast cancer: a population-based case-control study. Cancer Epidemiol Biomarkers Prev 2007;16:422-9.

16 Fuhrman BJ, Freedman DM, Bhatti P, et al. Sunlight, polymorphisms of vitamin Drelated genes and risk of breast cancer. Anticancer Res 2013;33:543-51.

17 Edvardsen K, Veierød MB, Brustad M, et al. Vitamin D-effective solar UV radiation, dietary vitamin D and breast cancer risk. Int J Cancer 2011;128:1425-33.

18 Lin S-W, Wheeler DC, Park Y, et al. Prospective study of ultraviolet radiation exposure and risk of cancer in the United States. Int J Cancer 2012;131:E1015-23.

19 Zamoiski RD, Freedman DM, Linet MS, et al. Prospective study of ultraviolet radiation exposure and risk of breast cancer in the United States. Environ Res 2016;151:419-27.

20 Kuper H, Yang L, Sandin S, et al. Prospective study of solar exposure, dietary vitamin D intake, and risk of breast cancer among middle-aged women. Cancer Epidemiol Biomarkers Prev 2009;18:2558-61.

21 Blackmore KM, Lesosky M, Barnett $\mathrm{H}$, et al. Vitamin D from dietary intake and sunlight exposure and the risk of hormone-receptor-defined breast cancer. Am J Epidemiol 2008;168:915-24.

22 Hiller TWR, O'Sullivan DE, Brenner DR, et al. Solar ultraviolet radiation and breast cancer risk: a systematic review and meta-analysis. Environ Health Perspect 2020;128:16002.

23 Nahar VK, Ford MA, Hallam JS, et al. Sociodemographic and psychological correlates of sun protection behaviors among outdoor workers: a review. J Skin Cancer 2013;2013:1-10.

24 Grandahl K, Eriksen P, Ibler KS, et al. Measurements of solar ultraviolet radiation exposure at work and at leisure in Danish workers. Photochem Photobiol 2018;94:807-14

25 Sowah D, Fan X, Dennett L, et al. Vitamin D levels and deficiency with different occupations: a systematic review. BMC Public Health 2017;17:519.

26 Pedersen CB. The Danish civil registration system. Scand J Public Health 2011;39:22-5.

27 Gjerstorff ML. The Danish cancer registry. Scand J Public Health 2011;39:42-5.

28 Blichert-Toft M, Christiansen P, Mouridsen HT. Danish Breast Cancer Cooperative Group--DBCG: History, organization, and status of scientific achievements at 30-year anniversary. Acta Oncol 2008;47:497-505.

29 Hansen J, Lassen CF. The supplementary pension fund register. Scand J Public Health 2011;39:99-102

30 Statistics D. Danmarks Statistik Erhvervsgrupperingskode, DSE 77. Copenhagen Statistics Denmark, 1989.

31 Nations U. International standard industrial classification of all economic activities. New York: United Nations, 1968.

32 Kauppinen T, Heikkilä P, Plato N, et al. Construction of job-exposure matrices for the Nordic occupational cancer study (NOCCA). Acta Oncol 2009:48:791-800.

33 Hansen EJ. Socialgrupper I Danmark. Copenhagen: Institute of Danish Social Science, 1984

34 Terry MB, Michels KB, Brody JG, et al. Environmental exposures during windows of susceptibility for breast cancer: a framework for prevention research. Breast Cancer Res 2019;21:96.

35 Grant WB. A review of the evidence supporting the vitamin D-Cancer prevention hypothesis in 2017. Anticancer Res 2018;38:1121-36.

36 Stevens RG. Circadian disruption and breast cancer: from melatonin to clock genes. Epidemiology 2005; 16:254-8.

37 Abbas MA. Physiological functions of vitamin D in adipose tissue. J Steroid Biochem Mol Biol 2017;165:369-81.

38 Kift R, Rhodes LE, Farrar MD, et al. Is sunlight exposure enough to avoid Wintertime vitamin D deficiency in United Kingdom population groups? Int J Environ Res Public Health 2018;15. doi:10.3390/ijerph15081624. [Epub ahead of print: 01 Aug 2018].

39 Holick MF. Sunlight and vitamin D for bone health and prevention of autoimmune diseases, cancers, and cardiovascular disease. Am J Clin Nutr 2004;80:1678S-88.

40 Rothman KJ. No adjustments are needed for multiple comparisons. Epidemiology 1990;1:43-6. 